University of Nebraska - Lincoln

DigitalCommons@University of Nebraska - Lincoln

January 1985

\title{
Radial Distribution of Dose and Cross-Sections for the Inactivation of Dry Enzymes and Viruses
}

Zhang Chunxiang

Zhongshan University, Guangshou, China

D. E. Dunn

University of Nebraska-Lincoln

Robert Katz

University of Nebraska-Lincoln, rkatz2@unl.edu

Follow this and additional works at: https://digitalcommons.unl.edu/physicskatz

Part of the Physics Commons

Chunxiang, Zhang; Dunn, D. E.; and Katz, Robert, "Radial Distribution of Dose and Cross-Sections for the Inactivation of Dry Enzymes and Viruses" (1985). Robert Katz Publications. 69.

https://digitalcommons.unl.edu/physicskatz/69

This Article is brought to you for free and open access by the Research Papers in Physics and Astronomy at DigitalCommons@University of Nebraska - Lincoln. It has been accepted for inclusion in Robert Katz Publications by an authorized administrator of DigitalCommons@University of Nebraska - Lincoln. 


\title{
Radial Distribution of Dose and Cross-Sections for the Inactivation of Dry Enzymes and Viruses
}

\author{
Zhang Chunxiang, ${ }^{1}$ D. E. Dunn, ${ }^{2}$ and R. Katz ${ }^{2}$ \\ ${ }^{1}$ Department of Physics, Zhongshan University, Guangshou, China \\ ${ }^{2}$ Department of Physics, University of Nebraska-Lincoln, Lincoln, NE 68588-0111, USA
}

\begin{abstract}
A new semi-empirical algorithm for the radial distribution of dose is compared with available data. The algorithm is used to calculate the inactivation cross section for dry enzymes and viruses using an extended target model of a 1-hit detector. Agreement with data is at about the 15\% level, approximating the precision of the data itself.
\end{abstract}

\section{Radial Distribution of Dose}

Track theory describes the interaction of a charged particle with a detector through the joint application of the radial distribution of dose and the dose-response function after irradiation with gamma rays. In the 20 years since this model was introduced, ${ }^{1-3}$ a number of measurements and calculations of the radial dose distribution have been made. To introduce these results into our calculations a semi-empirical formula for the radial distribution of dose has been developed, as shown in Table 1.

Our dose formula, Equation 1, Table 1, is based on a power law representation of the electron range-energy relationship, Equation 4, fitted separately to data for electrons below ${ }^{4}$ and above ${ }^{5} 1 \mathrm{keV}$, in aluminum. We assume the Rutherford cross section for delta ray production from atoms having ionization potential $\mathrm{I}=10 \mathrm{eV}$, Equation 8, normal ejection, and the Barkas formula for effective charge, Equation 10. While these procedures are somewhat arbitrary, the equation fits the available measurements ${ }^{6-9}$ and calculations ${ }^{10}$ rather well, as shown in Figure 1. We use this equation interpolatively to calculate the inactivation cross sections for dry enzymes and viruses, and, with trepidation, extrapolatively to calculate ion-kill cross sections for the inactivation of biological cells in the track width regime with ions up to uranium, well outside the region in which we can have confidence in the formula (Katz et al., this conference).

Our model needs extensive further measurements and calculations of the radial distribution of dose. At the very least we hope for experiments which lead to evaluation of an effective charge formula, based on stopping power, which is everywhere valid. An experimental program to determine the total cross section for delta ray production would also be helpful. But most important to us is the measurement of the radial distribution of dose, at all distances from the path of an energetic ion, from $10^{-10} \mathrm{~m}$ to the maximum radial penetration of delta rays.

Table 1. Formulae and constants for calculating the radial distribution of dose about the path of an energetic heavy ion in water.

\section{Radial dose distribution}

$$
\begin{array}{cc}
\mathrm{D}(\mathrm{t})=\left(\mathrm{Ne}^{4} \mathrm{Z}^{* 2} / \alpha \mathrm{mc}^{2} \beta^{2} \mathrm{t}\right) \cdot\{1-[(\mathrm{t}+\theta) /(\mathrm{T}+\theta)]\}^{1 / \alpha} /(\mathrm{t}+\theta) \\
\theta=\mathrm{R}(\mathrm{I}) & \mathrm{I}=10 \mathrm{eV} \\
\mathrm{T}=\mathrm{R}(\mathrm{W}) & \mathrm{W}=2 \mathrm{mc}^{2} \beta^{2}\left(1-\beta^{2}\right)^{-1 / 2}
\end{array}
$$

Electron range-energy relation for aluminum

$$
\begin{aligned}
& \mathrm{R}=\mathrm{kw} \mathrm{w}^{\alpha} \\
& \mathrm{k}=6 \times 10^{-6} \mathrm{~g} \cdot \mathrm{cm}^{-2} \cdot \mathrm{keV}^{\alpha} \\
& \mathrm{w}<1 \mathrm{keV}, \alpha=1.079 \text { for ion energy }<2 \mathrm{MeV} \cdot \mathrm{amu}^{-1} \\
& \mathrm{w}>1 \mathrm{keV}, \alpha=1.667 \text { for ion energy }>0.5 \mathrm{MeV} \cdot \mathrm{amu}^{-1}
\end{aligned}
$$

Delta ray distribution

$$
\operatorname{dn}=\left(2 \pi \mathrm{Ne}^{4} \mathrm{Z}^{* 2} / \mathrm{mc}^{2} \beta^{2}\right) \cdot \mathrm{dw} /(\mathrm{w}+\mathrm{I})^{2}
$$

Constant for liquid water

$$
2 \pi \mathrm{Ne}^{4} / \mathrm{mc}^{2}=1.369 \times 10^{-14} \mathrm{~J} . \mathrm{cm}^{-1}=8.5 \mathrm{keV} \cdot \mathrm{mm}^{-1}
$$

Effective charge from stopping power in emulsion, $\mathrm{Z}<18$

$$
Z^{*}=Z\left[1-\exp \left(-125 \beta Z^{-2 / 3}\right)\right]
$$



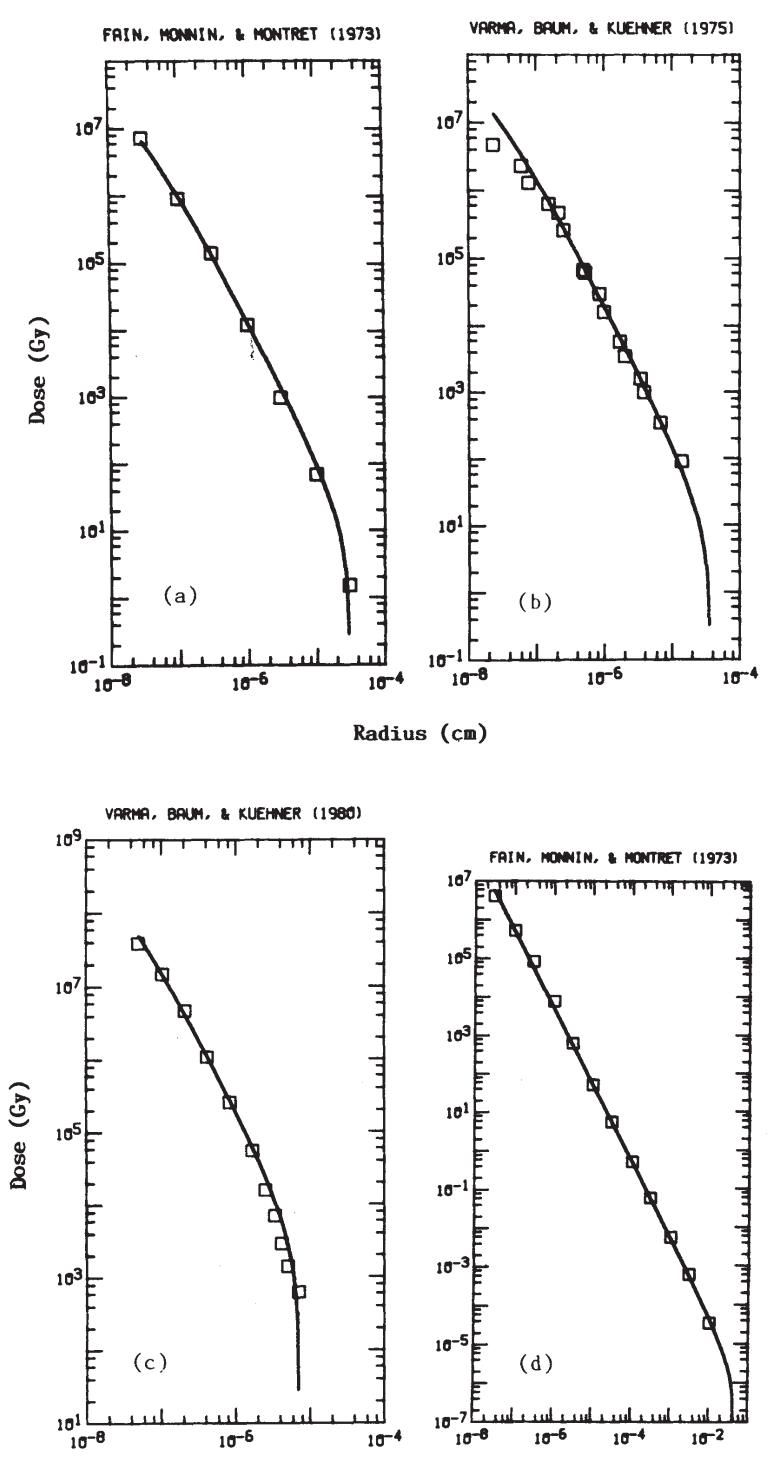

Radius $(\mathrm{cm})$

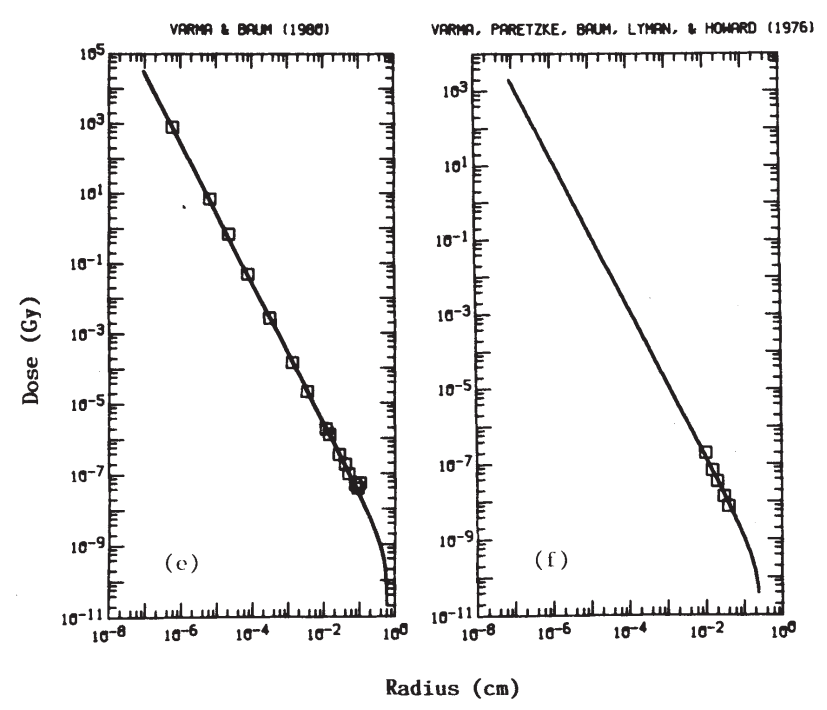

Figure 1. Comparison of the dose calculated from the formulae of Table 1 (curves) with the calculations of Fain et al.(10), and with the measurements of Varma et al., ${ }^{6-9}$ shown as squares. Note that the constants used in the range-energy relation are consistent with the ion energies, according to Equations 6 and 7 of Table 1. It is interesting and somewhat surprising that the use of an effective charge, Equation 10 of Table 1, and range-energy data for aluminum yield results close to those from measurement for partially stripped slow ions in gases.
Key: $\quad$ (a) ${ }_{6}^{12} \mathrm{C}, 2.0 \mathrm{MeV} \cdot \mathrm{amu}^{-1} \quad \alpha=1.08$
(b) ${ }_{8}^{16} \mathrm{O}, 38.4 \mathrm{MeV} \quad \alpha=1.08$
(c) ${ }_{35}^{79} \mathrm{Br}, 42.0 \mathrm{MeV} \quad \alpha=1.08$
(d) ${ }_{26}^{56} \mathrm{Fe}, 90.0 \mathrm{MeV} \cdot \mathrm{amu}^{-1} \quad \alpha=1.667$
(e) ${ }_{10}^{20} \mathrm{Ne}, 377.0 \mathrm{MeV} \cdot \mathrm{amu}^{-1} \quad \alpha=1.667$
(f) ${ }_{2}^{4} \mathrm{He}, 930.0 \mathrm{MeV} \quad \alpha=1.667$

\section{Inactivation Cross Sections}

Such has been the advance of computing technology that the calculation of the inactivation cross sections for dry enzymes and viruses in the point target model $^{2}$ can now be made on the Hewlett- Packard HP-41 hand held programmable calculator.

The work displayed here is done with an extended target model, with the enzyme or virus represented as a short cylinder whose axis is parallel to the ion's path. The average dose to the cylinder, whose axis is at radial distance $\mathrm{t}$ from the path is $\mathrm{E}(\mathrm{t})$. The cross section is then given as the radial integral of the inactivation probability, given for the 1-hit detector as

$$
\sigma=2 \pi \int_{0}^{\mathrm{T}}\left\{1-\exp \left[-\left(\mathrm{E}(\mathrm{t}) / \mathrm{E}_{0}\right)\right]\right\} \mathrm{tdt}
$$

where $E_{0}$ is the $D_{37}$ dose for gamma rays and $T$ is the greatest radial penetration of delta rays.

The original motive for the measurement of enzyme and virus inactivation cross sections was to determine the physical size of these entities. It was assumed that a high LET particle passing through an enzyme would always inactivate it, while if the particle passed outside, the enzyme would remain unharmed. This interpretation ignored the dominant effect of delta rays. In the present model target size plays a secondary role in the track width regime, where the inactivation cross section exceeds the physical size of the enzyme molecule. We have therefore assigned nominal target radii for calculational purposes of 10,30 , and $100 \AA$, when $\mathrm{E}_{0}$ lies in the decades $10^{5}, 10^{4}$, and $10^{3} \mathrm{~Gy}$, respectively, to approximate target volumes. Target size is more significant in our calculations in the grain count regime, and in the region of thindown, where there is little available data.

For simplicity in the presentation we have fitted the cross section data by assigning values of $\mathrm{E}_{0}$. Where an experimental $\mathrm{D}_{37}$ dose is available we compare the fitted to 
the experimental value. The average ratio of $\mathrm{D}_{37}$ (experimental) to $\mathrm{E}_{0}$ (fitted to cross section data) is $1.07 \pm 0.18$. This agreement is a substantial improvement over our earlier work, and is principally due to the improved expression for the radial dose distribution.

Our principal results are presented in Figures 2 and 3. Here we show the calculated cross sections as open circles or squares, and the measured cross sections as + or $x$, all plotted against LET. To nest the results for a more compact presentation, the data are shifted multiplicatively, by powers of 10 . The data are all identified by the first two letters of the name of the first author and the year of publication, for mnemonic purposes. The average ratio of the experimental to calculated cross sections is $0.96 \pm 0.11$. In Figure 2 we note a persistent trend in the enzyme data of Brustad (Br60, Br67) ${ }^{11,12}$ where the calculated cross section under-estimates the measured cross sections at low LET when $\mathrm{E}_{0}$ is fitted by matching the cross sections at high LET. No $\mathrm{D}_{37}$ dose is reported for these data. Fairly large and unexplained differences also exist at the low LET value for the ribonuclease data of Marshall et al. (Ma70) ${ }^{17}$ and for the trypsin data of Dolphin and Hutchinson (Do60). ${ }^{14}$

With the new expression for the radial dose distribution our calculations lie within approximately $15 \%$ of the experimental data.

\section{Comments}

There are some puzzling aspects of these results. Our dose formula fits the experimental data rather well. Experimentally there is no hint of a track core. Radial integration of our dose formula yields about half the stopping power. Thus the experimental radial dose measurements must also integrate to about half the stopping power. How is it that the dose measurements do not reveal all the deposited energy? How is it that a dose formula that produces only half the deposited energy is able to account for the entire cross section? Perhaps in answer to the second question there is already sufficient overkill from delta rays close to the ion's path for the additional energy from primary ionizations and excitations to have no influence on the cross section.

Many microdosimetrists believe that the resolution of radiobiological problems lies in knowledge of the detailed spectrum of energy depositions in nanometer or micrometer sub-volumes, and in the spectrum of separations of near neighbor ionizations. The present work demonstrates that to $15 \%$ accuracy, that is, to the accuracy of much of this experimental data, such detail is superfluous.

\section{Acknowledgement}

This work was supported by the US Department of Energy.

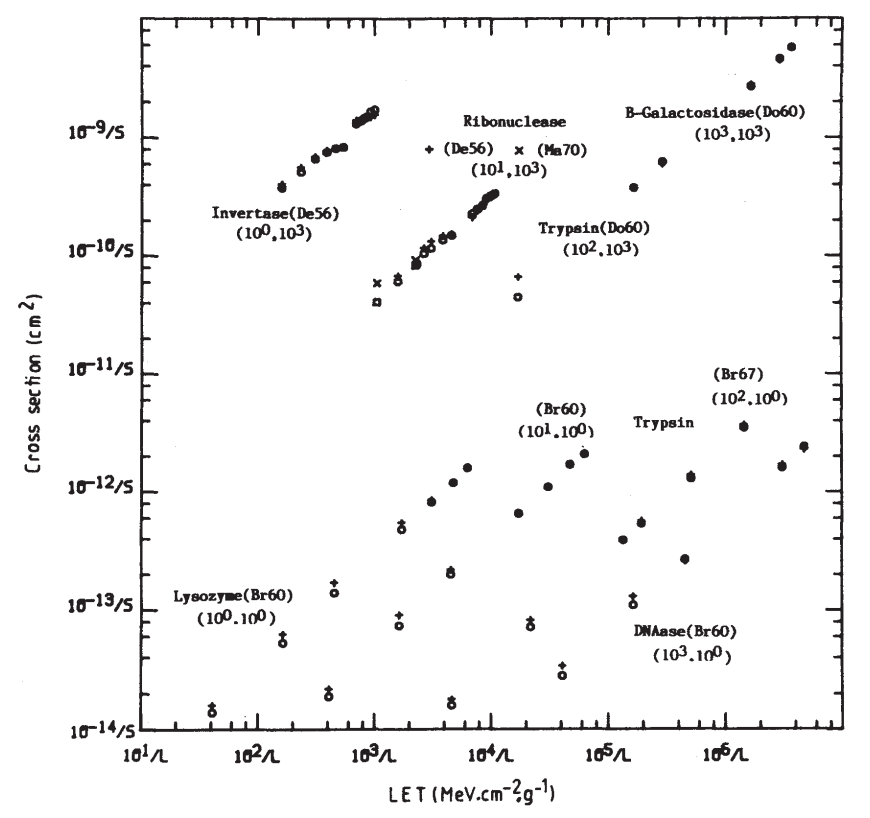

Figure 2. Measured cross sections for enzyme inactivation $\left(_{+}\right.$ $x)$ compared with values calculated from a single value of $E_{0}$ $(\circ, \square)$. Note the systematic disagreement at low LET between measurements by Brustad (Br60, Br67) and values calculated from an $\mathrm{E}_{0}$ giving best fit for high LET values. No explanation is offered. Shift on axes: L, LET axis; S, cross section axis. Key: Bracketed codes on the figure with corresponding numbers in the Reference List. (Br60) 11, (Br67) 12, (De56) 13, (Do60) 14, (Ma70) 17.

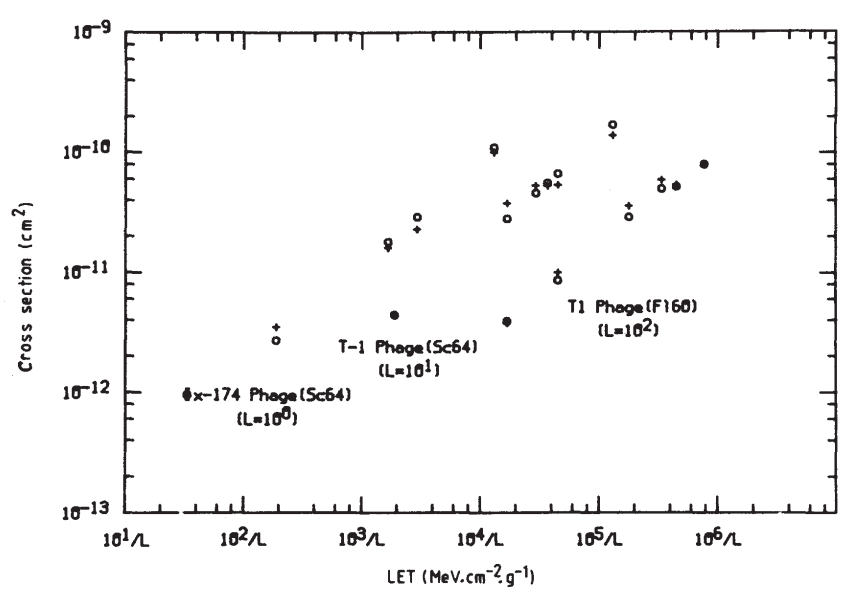

Figure 3. Measured and calculated cross sections for viruses. Key etc. as Figure 2 with, in addition, (F160) 15, (Sc64) 16. 


\section{References}

1. Katz, R. and Butts, J. J. Width of Ion andMonopole Tracks in Emulsion. Phys. Rev. 137, B198-B203 (1965).

2. Butts, J. J. and Katz, R. Theory of RBE for Heavy Ion Inactivation of Dry Enzymes and Viruses. Radiat. Res. 30, 855871 (1967).

3. Katz, R. and Kobetich, E. J. Particle Tracks in Emulsion. Phys. Rev. 186, 344-351 (1969).

4. Iskef, H., Cunningham, J. W., and Watt, D. E. Projected Ranges and Effective Stopping Powers of Electrons with Energy Between $20 \mathrm{eV}$ and $10 \mathrm{keV}$. Phys. Med. Biol. 28, 535545 (1983).

5. Kobetich, E. J. and Katz, R. Energy Deposition by Electron Beams and Delta Rays. Phys. Rev. 170, 391-396 (1968).

6. Varma, M. N., Baum, J. W., and Kuehner, A. V. Energy Deposition in a Tissue Equivalent Gas. Radiat. Res. 62, 1-11 (1975).

7. Varma, M. N., Baum, J. W., and Kuehner, A. V. Stopping Power and Radial Dose Distribution for $42 \mathrm{MeV}$ Bromine Ions. Radiat. Res. 81, 355-363 (1980).

8. Varma, M. N. and Baum, J. W. Energy Deposition in Nanometer Regions by $377 \mathrm{MeV} /$ nucleon ${ }^{20} \mathrm{Ne}$ Ions. Radiat. Res. 81, 355-363 (1980).

9. Varma, M. N., Paretzke, H. G., Baum, J. W., Lyman, J. T., and Howard, J. Dose as a Function of Radial Distance from a 930 $\mathrm{MeV}{ }^{4} \mathrm{He}$ Ion Beam. In: Proc. 5th Symp. on Microdosimetry, eds. J. Booz, H. G. Ebert, and B. G. R. Smith (Luxembourg: Commission of the European Communities) (1976).
10. Fain, J., Monnin, M., and Montret, M. Energy Density Deposited by a Heavy Ion Around its Path. In: Proc. 4th Symp. on Microdosimetry, eds. J. Booz, H. G. Ebert, R. Eickel, and A. Waker (Luxembourg: Commission of the European Communities) (1974).

11. Brustad, T. (Br60). Study of the Radiosensitivity of Dry Preparations of Lysozyme, Trypsin, and Deoxyribonuclease, Exposed to Accelerated Nuclei of $\mathrm{H}, \mathrm{He}, \mathrm{C}, \mathrm{O}, \mathrm{Ne} . \mathrm{R} a-$ diat. Res. Suppl. 2, 65-74 (1960).

12. Brustad, T. (Br67). Inactivation at Various Temperatures of the Esterase Activity of Dried Trypsin by Radiations of Different LET. Radiat. Res. Suppl. 7, 74-86 (1967).

13. Peering, R. A. (De56). Inactivation Cross Sections of Dried Invertase and Ribonuclease as a Function of LET. Radiat. Res. 5, 238-246 (1956).

14. Dolphin, G. W. and Hutchinson, F. (Do60). The Action of Fast Carbon and Heavier Ions on Biological Materials. Radiat. Res. 13, 403-414 (1960).

15. Fluke, D. J., Brustad, T., and Birge, A. C. (F160). Inactivation of Dry T-1 Bacteriophage by Helium Ions, Carbon Ions, and Oxygen Ions. Radiat. Res. 13, 788-808 (1960).

16. Schambra, P. E. and Hutchinson, F. (Sc64). The Action of Fast Heavy Ions on Biological Material. Radiat. Res. 23, 514- 526(1964).

17. Marshall, M., Holt, P. D., and Gibson, J. A. (Ma70). Physical Parameter of Radiations Determined from the Inactivation of Ribonuclease. Int. J. Radiat. Biol. 18, 139-146 (1970). 